\title{
Work With What You've Got
}

\author{
Lucy Bell \\ Xaad Kihlgaa Hl Suu.u Society \\ Box 543 \\ Old Massett, Haida Gwaii, BC \\ V0T $1 \mathrm{M} 0$ \\ lucybell@uvic.ca
}

\author{
Lawrence Bell \\ Lawrence Bell \\ ClO Simon Fraser University \\ First Nations Language Dept. \\ Burnaby, BC \\ V5A 1 S6
}

\begin{abstract}
It is a race against time when revitalizing an endangered language isolate. We learned an important lesson over the years: we learned to work with what we've got. We do not have time to reinvent the wheel or be indecisive in our language revitalization. With our fluent elders passing away at such a fast rate and new learners scrambling to learn Xaad Kil, we have to be efficient. We have to share resources between the dialects and value and learn from the precious resources we have each created. By sharing across the dialects, we have been able to quickly create new resources like a digital Haida phrasebook.
\end{abstract}

The Haida language is dangerously close to extinction. With only a couple handfuls of fluent speakers from Haida Gwaii, British Columbia and Southeast Alaska, it is a race against time to pass $\underline{X}$ aad Kil, the Haida language isolate to the next generation. As with many endangered languages, it is a struggle to create resources, interest and fluency on limited budgets. The Haida language is no exception.

Sharing resources is such an important part of indigenous language revitalization. Aboriginal languages are not like English, French, Spanish or German. There are not a ton of resources or a ton of speakers in the world.

Grassroots language revitalization was happening in southeast Alaska and on Haida Gwaii. There have been strong and very different efforts in all communities. For instance, in Skidegate, the Skidegate Haida Immersion Program focused on recording elders. In Massett, we developed a strong cohort of immediate language learners through accredited courses. In Alaska there were courses and publications happening. The International Haida Language conferences became a way to share resources, plan and work together on new projects. This became a valuable part of Xaad Kil revitalization. There was some sporadic communication between the communities but it wasn't until the International Haida language conferences that the sharing of resources and working towards a common orthography began. Once we began sharing dictionaries, glossaries, recordings and lessons our library of resources blossomed.

One of our successful cross-dialect initiatives was an adult accredited class offered to a cohort of 30+ students in Old Massett and in Ketchikan Alaska. The students in Alaska gathered with linguist Dr. Jordan Lachler. The Old Massett students gathered with elder Claude Jones. We worked from the Dii Tawlang lessons done by Dr. Lachler in the Alaskan dialect and orthography. We used the Haida health centre's video technology to connect to the Alaskans three evenings per week. The system was great when the technology worked. Having an elder in Massett present helped us tweak the lesson plans and all of the students were able to learn the subtleties between the two dialects. Not only did the students' language improve greatly, but our understanding of the dialect similarities and differences improved as well. This course was a good lesson in the importance of crosscommunication between dialects. 


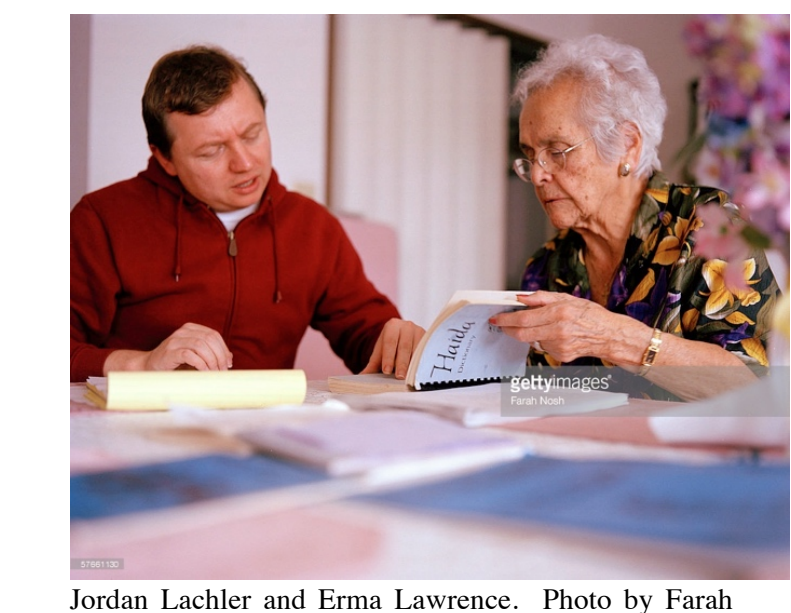
Nosh.

Jordan Lachler and Erma Lawrence. Photo by Farah

We began a partnership with the Simon Fraser University with a 7-year grant from SSHRC called First Nations Languages in the 21st Century: Looking Back, Looking Forward. The First Nations Language Centre at SFU coordinates many grassroots community projects across $\mathrm{BC}$ and academic linguists from SFU, UBC, UNBC, and many other universities to document, analyze, and revitalize Aboriginal languages.

We decided to develop language lessons in an App, focusing on the Skidegate and Northern (combined Alaskan and Massett) Haida dialects. We also decided to work with what we had and we focused on already-developed lessons. This saved valuable time and resources. The lessons were further developed, recorded with fluent elders and learners and put into the App. The Dii Tawlang App is a great introductory to the Haida language. This wasn't without challenges. There is great physical distance between the partners and the elders. This made it a timely process. With an aging population of fluent speakers, over time we lost valuable speakers who originally contributed to the project. The App has been tested by language learners on a small scale. The students agreed that the $40+$ online lessons were a valuable tool. We started to receive requests from schools, especially urban schools who want to offer their aboriginal students a second language other than French or Spanish. We realized that we needed to make the App more accessible and form relationships with educators to offer the Dii Tawlang App to a broader audience.

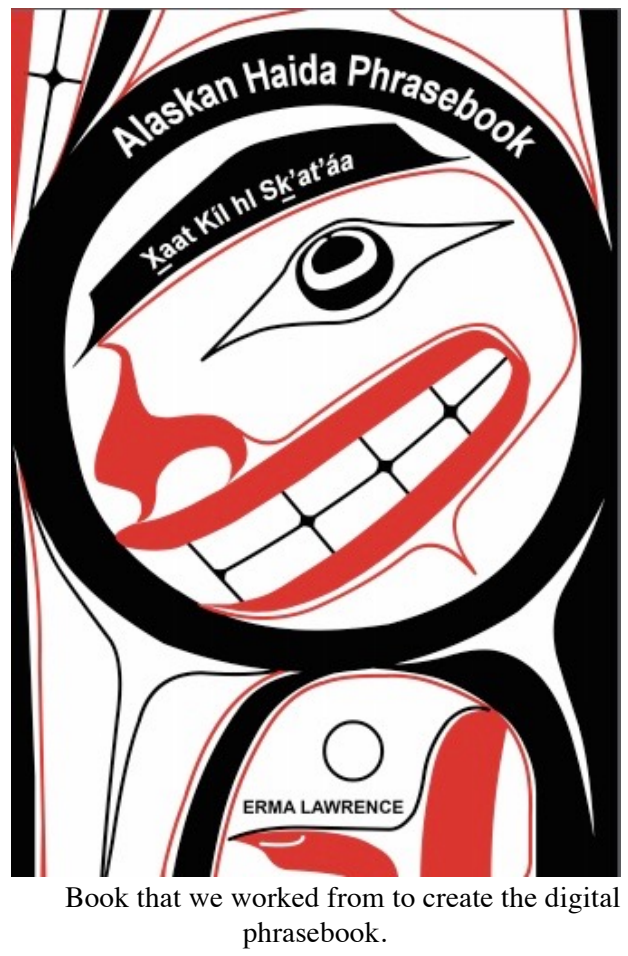

In 2017, we began working on a digital phrasebook to add to our App. Following our use what you got philosophy, we decided to take an existing book and digitize it. We worked from the 240-page Xaat Kil hl Sk'at'aa! Haida Phrasebook created by elder Erma Lawrence and Dr. Lachler in the Alaskan dialect (Lawrence, 2010). We chose this book to work from for a couple of reasons. First of all, the book is widely used by Massett learners. Most of the beginner and intermediate learners have an understanding of how to read the language and know how some of the subtle differences between the two dialects. It has been a valuable resource. We chose to digitize this book because students requested to hear the phrases. Dr. Lachler compiled the phrasebook with Erma Lawrence and informed us that he did not make a digital recording of the phrases but he thought it would be a useful tool to create. We also heard from northern Haidas that they enjoy accessing the Skidegate app but would prefer to have an App in the dialect of their ancestors. 
This work brought us together in Lawrence's hometown of Vancouver. We worked on the project together for four months. We translated the phrases in to our orthography, making slight adjustments to the spelling, added to the phrases and most importantly, recording the phrases in our northern Haida dialect. It was important for us to document and record the $200+$ pages of everyday phrases. We used the easy-to-use Amadeus Lite to make the recordings. For \$35, Amadeus Lite was a simple but effective program. We systematically went through the phrasebook, recording 12 pages per day and making notes and changes to the spelling and pronunciation along the way. Luckily, with our partnership with SFU, we were provided a classroom at the downtown campus to record in. To have our own soundproofed studio would have been ideal but we had to work with what we had. Some days were noisier than others, and we ended up having to re-record some of our work or I had to do extra editing.

After two months, we went back to Massett and showed a sample of the work to the beginner adult learners. They gave some valuable feedback. Some valuable advice they had included asking for a simple recording of the sounds of Xaad Kil and the dictionary. We have since compiled this. The students liked the format of the App since it follows the same format as the hardcover phrasebook that they have been using. It was also important for us to hear from learners how they would be using the digital phrasebook. All of them said they would prefer to use it on their phones or other devices while in a classroom situation and on their own. Students want to The App is being developed for smartphones.

We recorded the phrasebook for a total of 4 months. Then I began editing the 3000 raw sound-files. This was a tedious process and I recruited the help of my family, including my 7year-old niece Nora-Jane who became quite efficient at sound-file editing. From there, we compiled these into the App with the help of the SFU team after receiving a crash-course in inputting our data. I also recruited someone to input the written phrasebook to the App once I realized how much more work this would be.
The digital phrasebook could be used in a number of ways. First of all, language learners can put the App on their phones to learn from. Secondly, school programs can use the phrasebook alongside the recordings in their classrooms to teach students how to write the Haida language. The phrasebook could also be used by the many people who just want to learn a few phrases related to a specific topic. For instance, the fisheries department may use the phrases in their publications and around the office just as people can learn potlatch phrases when they are planning a potlatch.

We will store the sound files at SFU for future uses. The phrases are a good start towards a digital dictionary. By saving them at SFU, we can guarantee secure access to the files and we can work with SFU to ensure they are saved and distributed appropriately to the Haida community and partners in language revitalization.

The digital phrasebook work was good lesson for us. We learned that being a small team was more time efficient than having a big team. We also realized how important it is for the team to be in the same town! In the past, we relied on Lawrence coming to Massett once a month and squeezing in recording time with Dr. Ignace after they taught classes all day. With Lawrence being the only fluent male speaker of the Massett dialect, this has been such a valuable resource to create and it would not have happened if I did not move to Vancouver to work 1-on-1 with him on this project. Lawrence brought his language fluency and I brought my limited computer skills and Haida language reading and writing skills. Lastly, it was beneficial for us to learn how to input the data and create the App ourselves with the help of the SFU technical team.

On a personal level, the process of creating a digital phrasebook was beneficial for us both. It gave us valuable 1-on-1 time to pass the Haida language from a fluent speaker to a learner. This was quality mentoring time. The process was good for Lawrence because it greatly improved his $\underline{X}$ aad Kil reading skills. By the end of the four months, he was reading the Haida phrasebook like a pro. This process 
improved my speaking ability. The recording time with Lawrence as well as the editing time I put in to the project added to my fluency. I often refer to Lawrence as a walking Haida encyclopedia so the opportunity to sit with him for four months gave me the time to learn not only the Haida language but Haida genealogy and Haida history as well.

The lesson for us is that we have to use the resources we already have. We have to think creatively of the best way to quickly make resources and get them to learners. We have to think of our audience. We already had the phrasebook in another dialect. We already had a good working relationship with a University to create the App. We were also already willing and capable of recording, writing and inputting the data into the app. By working with our already existing resources and working with our existing relationships, we were able to create a valuable everyday digital phrasebook.

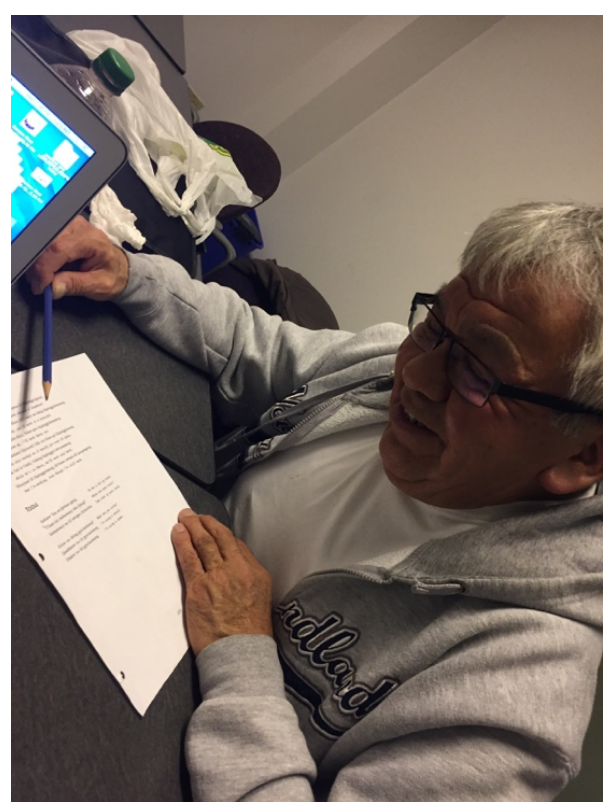

Lawrence Bell. A typical day at work. Photo by Lucy Bell.

\section{Acknowledgements}

We are grateful for the work of Erma Lawrence and Jordan Lachler who created the Alaskan Haida Phrasebook, Xaat Kil hl Sk'at'aa. Your valuable work has guided us to create the digital version of the book. Haw.aa.
We are also so grateful for SFU and the SSHRC partnership grant that allowed us the time, space and funding to create this resource.

\section{References}

Lachler, Jordan. 2010. Dictionary of Alaskan Haida. Sealaska Heritage Institution, Juneau, AK.

Lawrence, Erma. 2010. Xaat Kil hl Sk'at'aa! Haida Phrasebook. Sealaska Heritage Institute, Juneau, AK. 